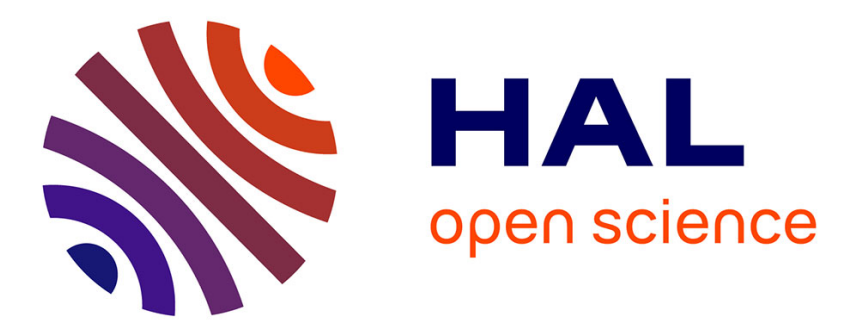

\title{
Characterization of thin films using generalized lamb wave dispersion relations
}

\author{
Patrick Richard, O. Behrend, G. Gremaud, A. Kulik
}

\section{To cite this version:}

Patrick Richard, O. Behrend, G. Gremaud, A. Kulik. Characterization of thin films using generalized lamb wave dispersion relations. Journal de Physique IV Proceedings, 1993, 03 (C7), pp.C7-2173-C72176. 10.1051/jp4:19937346 . jpa-00251994

\section{HAL Id: jpa-00251994 https://hal.science/jpa-00251994}

Submitted on 1 Jan 1993

HAL is a multi-disciplinary open access archive for the deposit and dissemination of scientific research documents, whether they are published or not. The documents may come from teaching and research institutions in France or abroad, or from public or private research centers.
L'archive ouverte pluridisciplinaire HAL, est destinée au dépôt et à la diffusion de documents scientifiques de niveau recherche, publiés ou non, émanant des établissements d'enseignement et de recherche français ou étrangers, des laboratoires publics ou privés. 


\title{
Characterization of thin films using generalized lamb wave dispersion relations
}

\author{
P. RICHARD, O. BEHREND, G. GREMAUD and A. KULIK \\ Ecole Polytechnique Fédérale de Lausanne, Département de Physique, Institut de Génie Atomique, \\ 1015 Lausanne, Switzerland
}

\begin{abstract}
We used the Continuous Wave Scanning Acoustic Microscope to characterize thin film materials. The measurement of the dispersion curve of surface waves and the inversion of this dispersion equation relation, allow to determine the elastic constants, the density or the thickness of a thin layer on a substrate. Besides, it is possible to have qualitative information on the adhesion properties of the layer.
\end{abstract}

\section{INTRODUCTION}

Applications of the point-focus-beam acoustic microscope to quantitative material characterization have been developed extensively through the $\mathrm{V}(\mathrm{z})$ curve[1]. Thus far a reliable measure of bond strength has to date not materialized. Acoustic microscopy studies have shown evidence of complete disbonds[2]. What is not evident is the ability of this technique to discern the interface differences between a perfect bond and the total delamination of the layer. On this particular point, some experimental and theoretical demonstrations have indicated the possible utility of surface acoustic waves in the detection of contact defects $[3,4,5]$. Generalized Lamb waves appear to be particularly useful in this regard.

The original aspect of our technique is the use of the Continuous Wave (CW) Scanning Acoustic Microscope (SAM) ${ }^{[6]}$ to excite and to measure these surface modes. We have simultaneously access to localized parameters as adhesion and elastic modulus, density or thickness of the layer through the numerical inversion of generalized Lamb waves' dispersion equation. The mapping on a larger scale is also possible. The ultrasonic frequency range available extends from $10 \mathrm{MHz}$ up to $2 \mathrm{GHz}$.

\section{THEORETICAL MODELS}

\subsection{Generalized Lamb waves}

In the abscence of piezoelectric effects and external forces the wave equation for the displacement in a perfect elastic medium is given by the elastic wave equation:

$$
\rho_{0} \frac{\partial^{2} u_{j}}{\partial t^{2}}=C_{i j k l} \frac{\partial^{2} u_{k}}{\partial x_{i} \partial x_{l}},
$$

where the $u_{j}$ is the displacement amplitudes, $\rho_{0}$ the mass density and $C_{i j k l}$ the stiffness tensor. For a thin isotropic and homogeneous layer of a material $A$, deposited on a semi-infinite isotropic and 
homogeneous substrate of a material $\mathrm{B}$, the boundary condition that has to be satisfied at the free surface $\left(x_{3}=0\right)$ implies solution of the form

$$
u_{j}=\alpha_{j} \exp \left[i k b x_{3}\right] \exp \left[i k\left(x_{1}+x_{2}-v t\right)\right]
$$

This solution describes generalized Lamb waves ${ }^{[7]}$ localized at the interface $x_{3}=0$, and propagating along the $x_{1}$ axis. To be called surface waves, the quantity $b$ in each terms of the solution must be a purely imaginary constant. For this type of surface waves, the particle motion under the free surface describes an ellipse lying in the sagittal plane.

\subsection{Dispersion relation}

The dispersion relation for generalized Lamb waves propagating in the thin layer on a substrate is obtained by solving the elastic wave equation (1) using the adequate boundary conditions ${ }^{[7]}$ and a solution of the form (2). This resolution yields

$$
\operatorname{det}[M]=0
$$

where $M$ is a 6 by 6 matrix depending on the characteristics of the layer (transverse and longitudinal wave velocity, density and thickness) and those of the substrate.

\section{EXPERIMENTAL TECHNIQUES AND SAMPLES}

The SAM we used in our measurements is built using a commercial acoustic lens and a network analyser that produces and detects the continuous wave ultrasound ${ }^{[6]}$. The $S_{11}$ parameter (complex ratio between the reflected wave amplitude and the incident one) for the transducer-lens-water-sample system is measured. By scanning the spherical lens-sample distance we obtain the continuous wave V(z) curve. We generate the FFT of this curve to separate the standing waves in water and the Surface Acoustic Wave (SAW) at the interface between water and sample. From this measurement it is possible to obtain the SAW velocity. The experimental dispersion curve is the plot of these points versus the frequency.

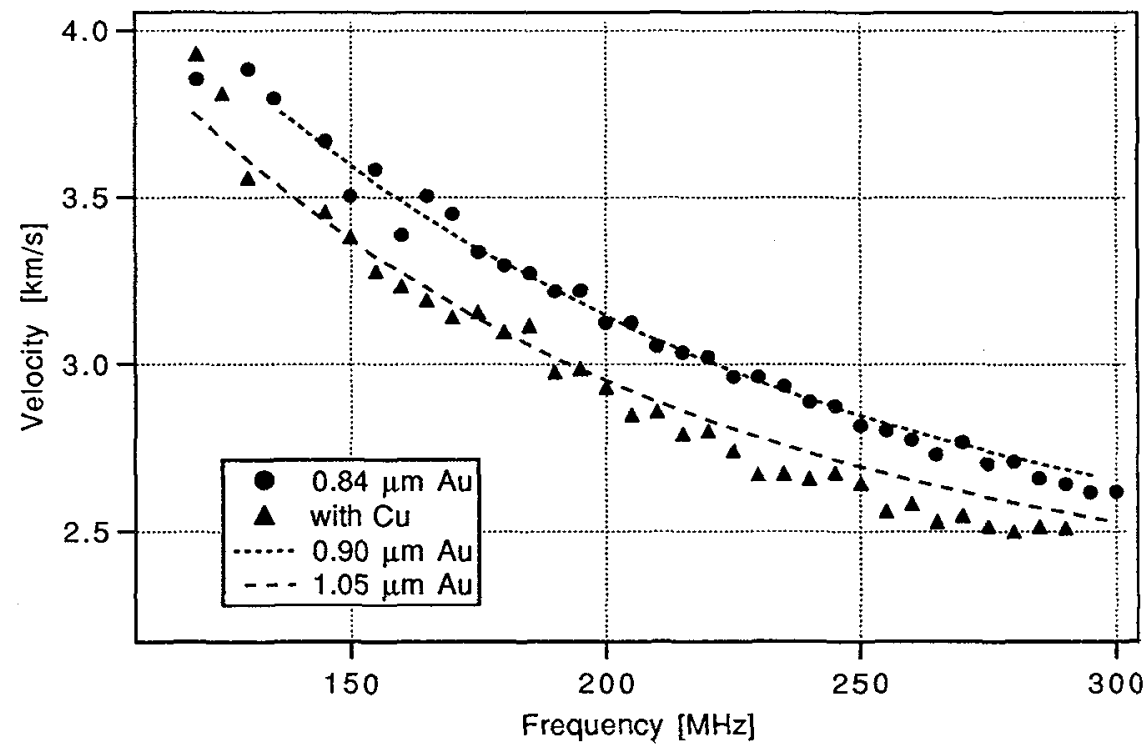

Fig. 1: Experimental ( $\bullet$ ) and calculated dispersion curves for a 0.84 um gold film on fused quartz. The upper dashed curve is the fitted one with the regression parameters (for elastic constants determination). The second measurement (A) is the same case with a copper intermediate layer. And the corresponding dashed curve is the dispersion relation resolved for a $1.05 \mu \mathrm{m}$ gold film. 
The film used for the elastic constants' determination was a $0.84 \mu \mathrm{m}$ thick gold layer deposited by sputtering on a $1 \mathrm{~mm}$ thick fused quartz substrate.

For the adhesion study, we have used a $3.2 \mu \mathrm{m}$ thick nickel film deposited by electroplating on a $5 \mathrm{~mm}$ thick aluminium alloy substrate, with a copper adhesive layer in between.

\section{RESULTS AND DISCUSSION}

\subsection{Characterization of thin films: elastic constants}

We perform $\mathrm{V}(\mathrm{z})$ measurements as a function of working frequency, inside the whole bandwidth of the lens and calculate the SAW velocity. For the previous described gold film, the first higher mode was excited and measured. Figure 1 shows the measured data of the dispersion curve $(\bullet)$ and the fitted theoretical curve (top dashed line); agreement is seen to be excellent.

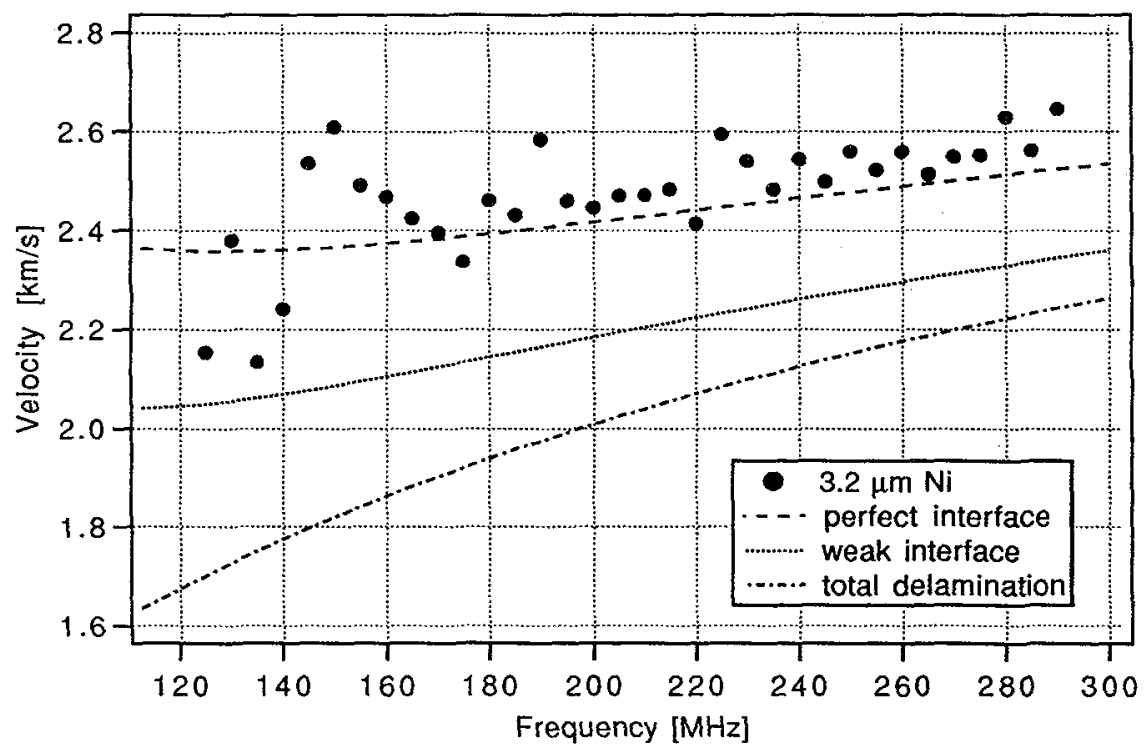

Fig. 2: Experimental ( $\cdot$ ) and calculated dispersion curves for a $3.2 \mu \mathrm{m}$ Ni film on Al alloy with a Cu adhesive layer in between. The upper dashed curve is calculated for perfect interface. The one in the middle is for weak interface and the lowest one is for total delamination of the layer.

Using the numerical inversion algorithm with the transverse wave velocity in the layer, the thickness and density of the layer as the regression parameters, we obtain from this data the Young's modulus $\mathrm{E}$, the Poisson's coefficient $v$ and the thickness $\mathrm{h}$ of the gold layer: $\mathrm{E}=78.88 \mathrm{GPa}, v=0.42$, $\mathrm{h}=0.90 \mu \mathrm{m}$ respectively.

The tabulated bulk values for these constants are $78.0 \mathrm{GPa}$ and 0.44 respectively[8]. The problem of convergence of the regression algorithm is discussed by Behrend et al[9].

Surface values, slightly different from the bulk values are used as input values for the adhesion characterization. The layer thickness is generally difficult to obtain with sufficient precision. In this way, it is interesting to notice that the thickness is the most modified parameter by the regression $(+6.8 \%$ of the nominal thickness). 


\subsection{Characterization of thin films: adhesion}

Knowing that the SAW velocity varies with the boundary condition at the interface and analysing the correlation between experimental dispersion curve and calculated dispersion relation from (3), for a given layer thickness and boundary condition, it is possible to extract useful information on adhesion.

Figure 2 presents the experimental data $(\bullet)$ and the calculated theoretical dispersion curve (top dashed line) corresponding to this case (with the surface values for the layer, it's nominal thickness and the bulk values for the substrate). The two other curves are calculated for the weak adhesion case (middle one) and for the total decohesion of the layer (bottom one).

By comparison of the position and shape of experimental and calculated dispersion curve, using different models for the boundary conditions, we can deduce that this nickel layer presents a very good bonding to its substrate. This is mainly due to the substrate preparation and the deposition technique. In addition to this, we know by a destructive technique that this case corresponds to very good bonding quality.

If the layer thickness is not well known, it is more difficult to obtain the adhesion information (see figure 1, lowest curve). The differences between a thicker film, a lower adhesion quality or the influence of the intermediate layer are now still not well established.

\section{CONCLUSION}

Continuous wave acoustic microscopy method was successfully applied to determine the elastic constants and the thickness for a gold layer on a fused quartz substrate. The Young's modulus was found to be slightly higher than the gold one for bulk, while the Poisson's coefficient was found to be somewhat lower than its bulk value.

In addition, the developed method can provide important information on the adhesion properties of the layer. The good adhesive case was emphasized with a nickel layer on aluminium.

\section{REFERENCES}

1. A. Briggs, Acoustic Microscopy. R. Brook, P. B. Hirsch, C. J. Humphreys, N. F. Mott, Eds., Monographs on the Physics and Chemistry of Materials (Oxford University Press, Oxford, 1992), vol. 47.

2. G. Gremaud, A. Kulik, S. Sathish, Europhys. News 22, 167-170 (1991).

3. J. Kushibiki, T. Ishikawa, N. Chubachi, Appl. Phys. Lett. 57, 1967-1969 (1990).

4. P.-C. Xu, A. K. Mal, Y. Bar-Cohen, Int. J. Engng. Sci. 28, 331-346 (1990).

5. L. Adler, M. D. Billy, G. Quentin, J. Appl. Phys. 68, 6072-6076 (1990).

6. A. Kulik, G. Gremaud, S. Sathish, Continuous Wave Reflection Scanning Acoustic Microscope, H. Schimizu, N. Chubachi, J. Kushibiki, Eds., Acoustical Imaging (Plenum Press, New-York, 1989), vol. 17, pp. 71-78.

7. B. A. Auld, Acoustic Fields and Waves in Solids (John Wiley \& Sons, New York, 1973), vol. 2.

8. G. W. C. Kaye, T. H. Laby, Tables of Physical and Chemical Constants and Mathematical Functions (Longmann, London, 1973).

9. $\quad$ O. Behrend, A. Kulik, G. Gremaud, Appl. Phys. Lett, To be published. 